\title{
Intense pulsed light sintering of copper nanoink for printed electronics
}

\author{
Hak-Sung Kim • Sanjay R. Dhage · Dong-Eun Shim • \\ H. Thomas Hahn
}

Received: 19 May 2009 / Accepted: 22 July 2009 / Published online: 5 August 2009

(C) The Author(s) 2009. This article is published with open access at Springerlink.com

\begin{abstract}
An intense pulsed light (IPL) from a xenon flash lamp was used to sinter copper nanoink printed on lowtemperature polymer substrates at room temperature in ambient condition. The IPL can sinter the copper nanoink without damaging the polymer substrates in extremely short time ( $2 \mathrm{~ms})$. The microstructure of the sintered copper film was investigated using X-ray powder diffraction (XRD), optical microscopy, scanning electron microscopy (SEM), X-ray micro tomography, and atomic force microscopy (AFM). The sintered copper film has a grainy structure with necklike junctions. The resulting resistivity was $5 \mu \Omega \mathrm{cm}$ of electrical resistivity which is only 3 times as high as that of bulk copper. The IPL sintering technique allows copper nanoparticles to be used in inkjet printing on low-temperature substrates such as polymers in ambient conditions.
\end{abstract}

PACS 71.20.Gj · 72.15.-v · 73.22.Dj · 73.61.At · 81.20.Ev

\section{Introduction}

Printed electronics techniques such as inkjet printing and flexo-printing present a low-cost solution to the production of electronic devices such as radio frequency identification

H.-S. Kim ( $\varangle)$ · S.R. Dhage · D.-E. Shim · H.T. Hahn

Mechanical and Aerospace Engineering Department, University of California, Los Angeles, CA 90095, USA

e-mail:kima1774@ucla.edu

Fax: +1-310-206-4830

H.T. Hahn

Material Science and Engineering Department, California NanoSystems Institute, University of California, Los Angeles, CA 90095, USA
(RFID) tags and large-area displays as they can do away with the time consuming and expensive processes inherent in the conventional photolithographic techniques used in the PCB (printed circuit board) industry [1]. Key components of printed electronics are conducting lines and films. Although conducting polymers could be used for these components, their conductivity and stability are still much inferior to those of their metallic counterparts [2-4]. Therefore, metal-based nanoinks have recently been introduced to alleviate these shortcomings. For the metal-based nanoinks, the need for low-temperature, in-situ sintering of conductive electrodes is an important issue. Kim et al. [2] developed Ag nanoparticle ink for inkjet printing where the nanoparticles could be sintered at temperatures around $200^{\circ} \mathrm{C}$ for $30 \mathrm{~min}$. They investigated the resistance changes of the inkjet printed conductive films with respect to the sintering temperature and $\mathrm{Ag}$ particle size. Ko et al. [4] studied sintering of gold nanoink on a polymer substrate using a 520-nm laser. They obtained a high line resolution down to $1-2 \mu \mathrm{m}$ with a low resistivity of $5.41 \mu \Omega \mathrm{cm}$, which is only two times that of bulk gold $(2.65 \mu \Omega \mathrm{cm})$. However, this local laser sintering technique requires a sophisticated 3D gantry system. In addition, since this technique can only sinter very small spots, it is difficult to cover large areas.

Although novel materials such as silver and gold can be sintered at fairly low temperatures, they are too expensive to be used for mass production. Therefore, Park et al. [3] developed a low-viscosity conductive ink containing welldispersed copper nanoparticles through a polyol process. The inkjet printed nanoparticles were sintered at $325^{\circ} \mathrm{C}$ for $1 \mathrm{~h}$ in vacuum to prevent oxidation [3]. However, the traditional thermal sintering still requires a high temperature, long cycle time and a vacuum chamber. 
Fig. 1 Schematic of intense pulsed light sintering system: (a) overall system; (b) xenon flash lamp setup
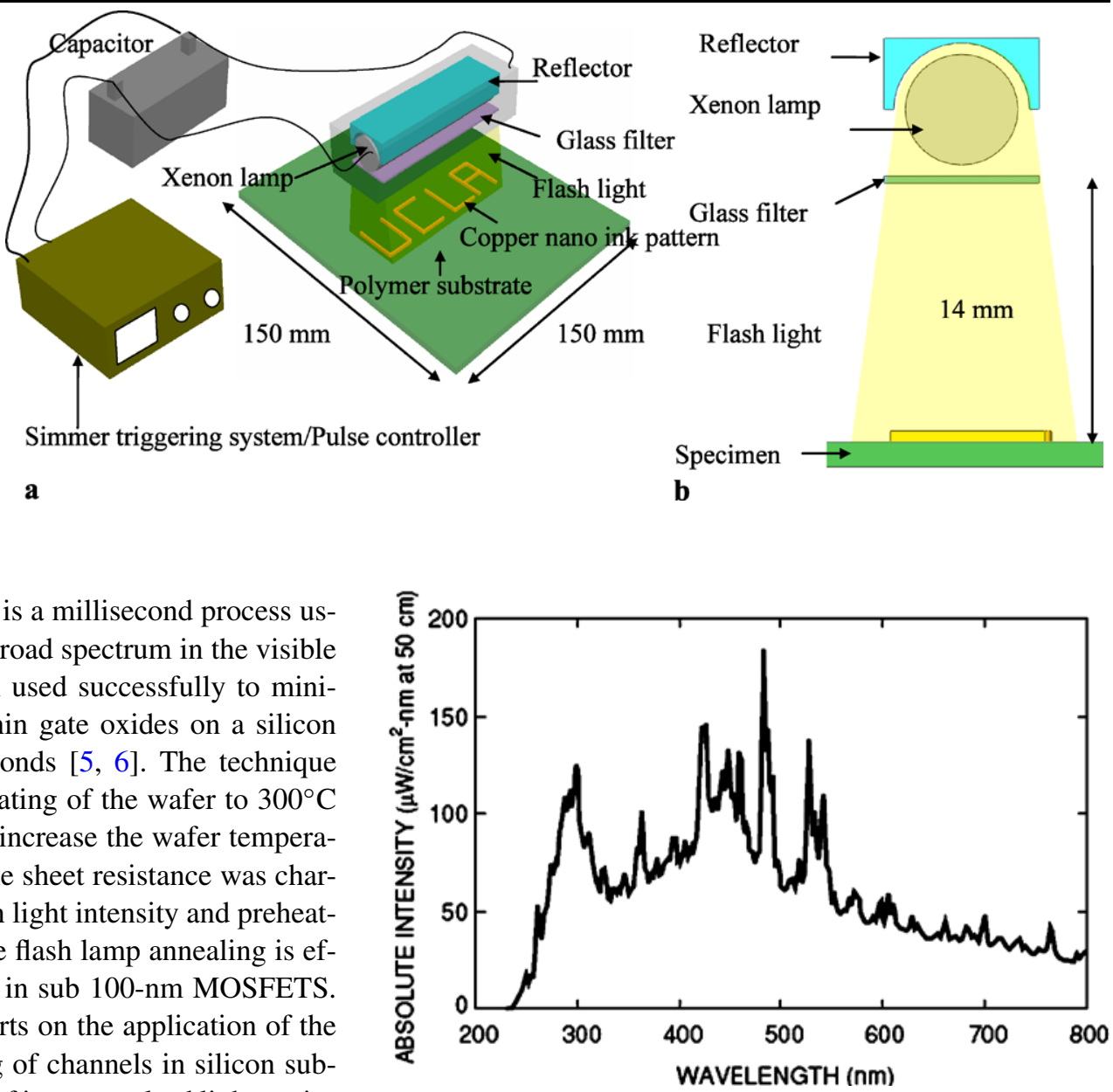

Flash lamp annealing (FLA) is a millisecond process using irradiation of lights over a broad spectrum in the visible range. This technique has been used successfully to minimize the annealing cycle for thin gate oxides on a silicon wafer to within a few milliseconds [5, 6]. The technique used a halogen lamp for pre-heating of the wafer to $300^{\circ} \mathrm{C}$ and then a xenon flash lamp to increase the wafer temperature to $600-700^{\circ} \mathrm{C}$ instantly. The sheet resistance was characterized as function of the flash light intensity and preheating temperature to show that the flash lamp annealing is effective for channel engineering in sub 100-nm MOSFETS. Although there are several reports on the application of the FLA technique to the annealing of channels in silicon substrates, the literature on the use of intense pulsed light to sinter conductive nanoparticles for printed electronics is rare to the authors' knowledge.

In the present work, we have developed an intense pulsed light (IPL) sintering technique for millisecond, large area sintering of copper conductive paths in ambient conditions. Commercial copper nanoink was painted on several polymer substrates and sintered using a xenon flash lamp system under varying levels of light intensity. The resulting conductivity was measured and correlated with microstructures examined by atomic force microscopy (AFM), X-ray diffraction (XRD), scanning electron microscopy (SEM), and $\mathrm{X}$-ray micro tomography.

\section{Experimental procedure}

The nanoink has copper particles of 5-nm diameter uniformly dispersed in a mixed solvent of ethylene glycol and 2-methoxyethanol (Samsung Electro-Mechanic, Korea). About $5 \mu$ of copper nanoink was dropped and spread uniformly over a square area $10 \mathrm{~mm} \times 10 \mathrm{~mm}$ using an auto pipette. The solvent was dried out at $80^{\circ} \mathrm{C}$ for $10 \mathrm{~min}$ and $1 \mu \mathrm{m}$ thick copper particles film was obtained. Also, a rubber stamp was used to make a copper nanoink pattern on the polymer substrate. For the substrate, four different materials were used: glass fiber BT (bismaleimide triazine) epoxy composite, polyimide film (Kapton, Dupont), polyethylene (PE) film, and polypropylene (PP) film. The intense pulsed light (IPL) sintering system was set up as shown in Fig. 1.

The IPL sintering system is composed of a xenon flash lamp (PerkinElmer QXA, UK), an aluminum reflector, a power supply, capacitors, a simmer triggering pulse controller, and a light filter. IPL is generated using an arc plasma phenomenon in the xenon flash lamp [7]. Once the gas is ionized, a spark is formed between the electrodes, allowing the capacitor current to conduct, which is the arc plasma phenomenon. A charged super capacitor $(40000 \mu \mathrm{F})$ is used to deliver high electrical current (about $1000 \mathrm{~A}$ ) in a short time $(1-10 \mathrm{~ms})$ when the lamp is triggered. During the arc plasma generation, the flash lamp emits an optical spectrum of light that covers a wide range of wavelength from $160 \mathrm{~nm}$ to $2.5 \mathrm{~mm}$ [7]. The conversion of electrical input power into radiated optical power is approximately $50 \%$ in the wavelength range of 200-1100 nm, Fig. 2 [7].
Fig. 2 Spectral distribution of a xenon flash lamp [7] 
Fig. 3 Schematic of intense pulsed light sintering process
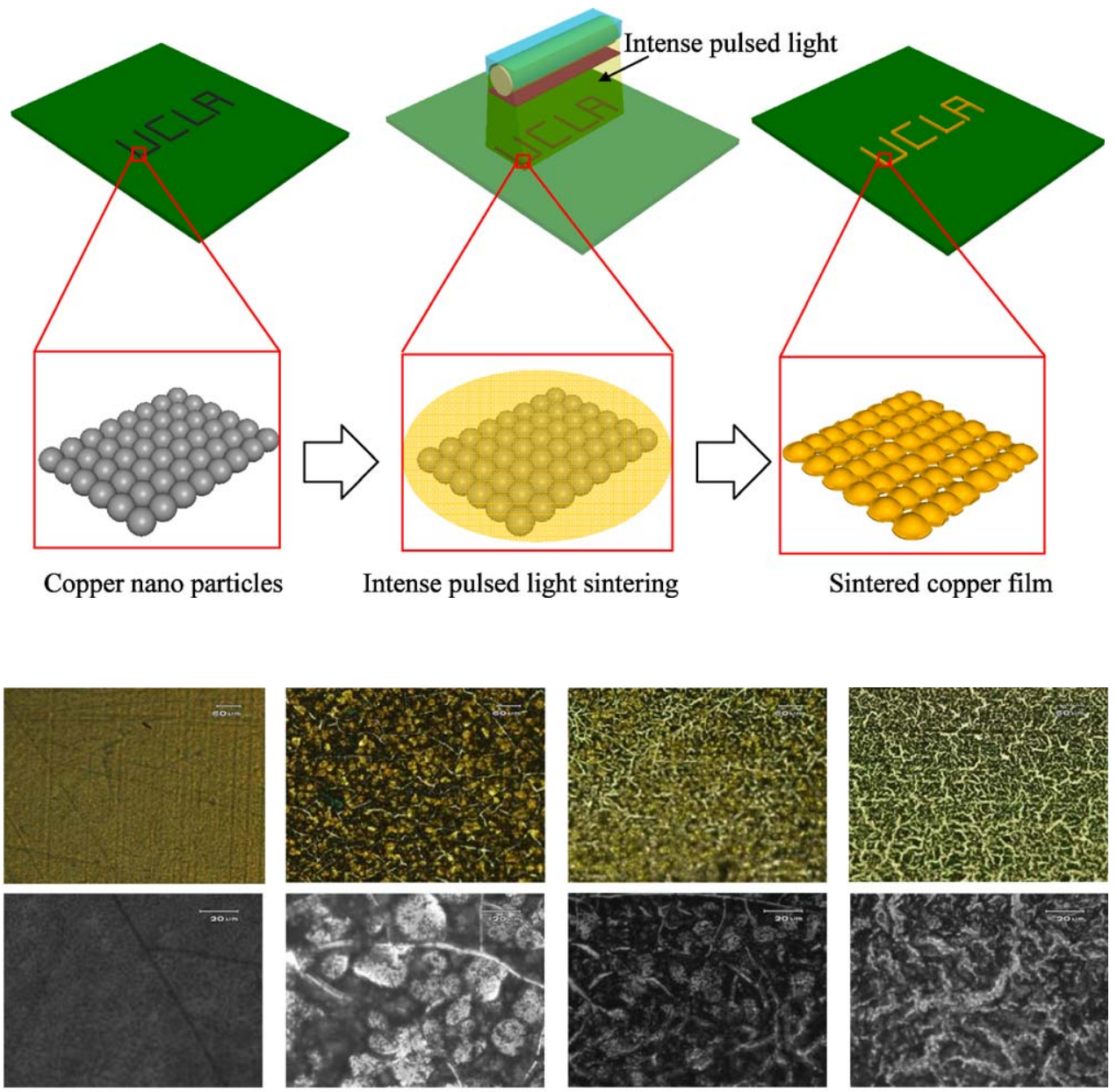

b

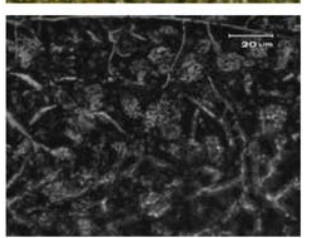

c

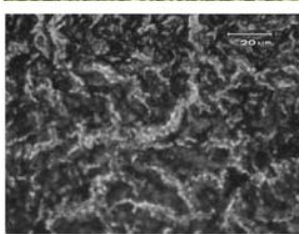

d
The energy of the light pulse can be controlled from 20 to $50 \mathrm{~J} / \mathrm{cm}^{2}$ by varying the capacitor charge, which was measured and verified at $14 \mathrm{~mm}$ distance from the lamp by the manufacturer [7]. Pulse durations from 2 to $10 \mathrm{~ms}$ are possible depending on the capacitor/inductor circuit configuration in the simmer triggering system.

In the present work, the pulse width was fixed at $2 \mathrm{~ms}$. Since the ultraviolet (UV) light may degrade polymer substrates, wavelengths below $540 \mathrm{~nm}$ were blocked out by a glass filter, as shown in Fig. 1 [8]. Then, the light irradiation was decreased to $70 \%$ of the initial irradiation by UV light filter [7]. The IPL sintering process was performed in ambient conditions as shown in Fig. 3.

The surface topography of the sintered film was investigated using various types of microscopes: an Olympus optical microscope, a field emission SEM (JEOL JSM67) with EDX, and an AFM (Digital Instrument Dimension 3100). The crystal phase analysis was done by XRD (Phillips, $\mathrm{Cu} \mathrm{K} \alpha$ radiation), and the microstructure was investigated using 3D X-ray microtomography (Micro Pho- tonics, Skyscan 1172). Electrical resistivity of the sintered copper film was measured using a 4-wire Kelvin measurement system (Keithley 2400).

\section{Results and discussion}

The IPL was irradiated on the copper nanoink for $2 \mathrm{~ms}$, $14 \mathrm{~mm}$ away from the specimen. The micrographs in Fig. 4 show the copper nanoparticles in aggregates when the light intensity is larger than $40 \mathrm{~J} / \mathrm{cm}^{2}$. When the light intensity is lower than $30 \mathrm{~J} / \mathrm{cm}^{2}$, large cracks are present and no particle agglomeration is observed.

The AFM micrographs in Fig. 5 show the clumped particle size increasing with increasing light intensity, which is in agreement with the SEM micrographs of Fig. 6. The SEM micrographs also show a clear grain of full sintering as indicated by the formation of necks between neighboring nanoparticles when the light intensity is higher than $45 \mathrm{~J} / \mathrm{cm}^{2}$. 
Fig. 5 AFM micrographs of copper nanoink sintered at: (a) unsintered; (b) $40 \mathrm{~J} / \mathrm{cm}^{2}$; (c) $50 \mathrm{~J} / \mathrm{cm}^{2}$

Fig. 6 SEM micrographs of copper nanoink sintered at: (a) unsintered; (b) $30 \mathrm{~J} / \mathrm{cm}^{2}$; (c) $40 \mathrm{~J} / \mathrm{cm}^{2}$; (d) $50 \mathrm{~J} / \mathrm{cm}^{2}$
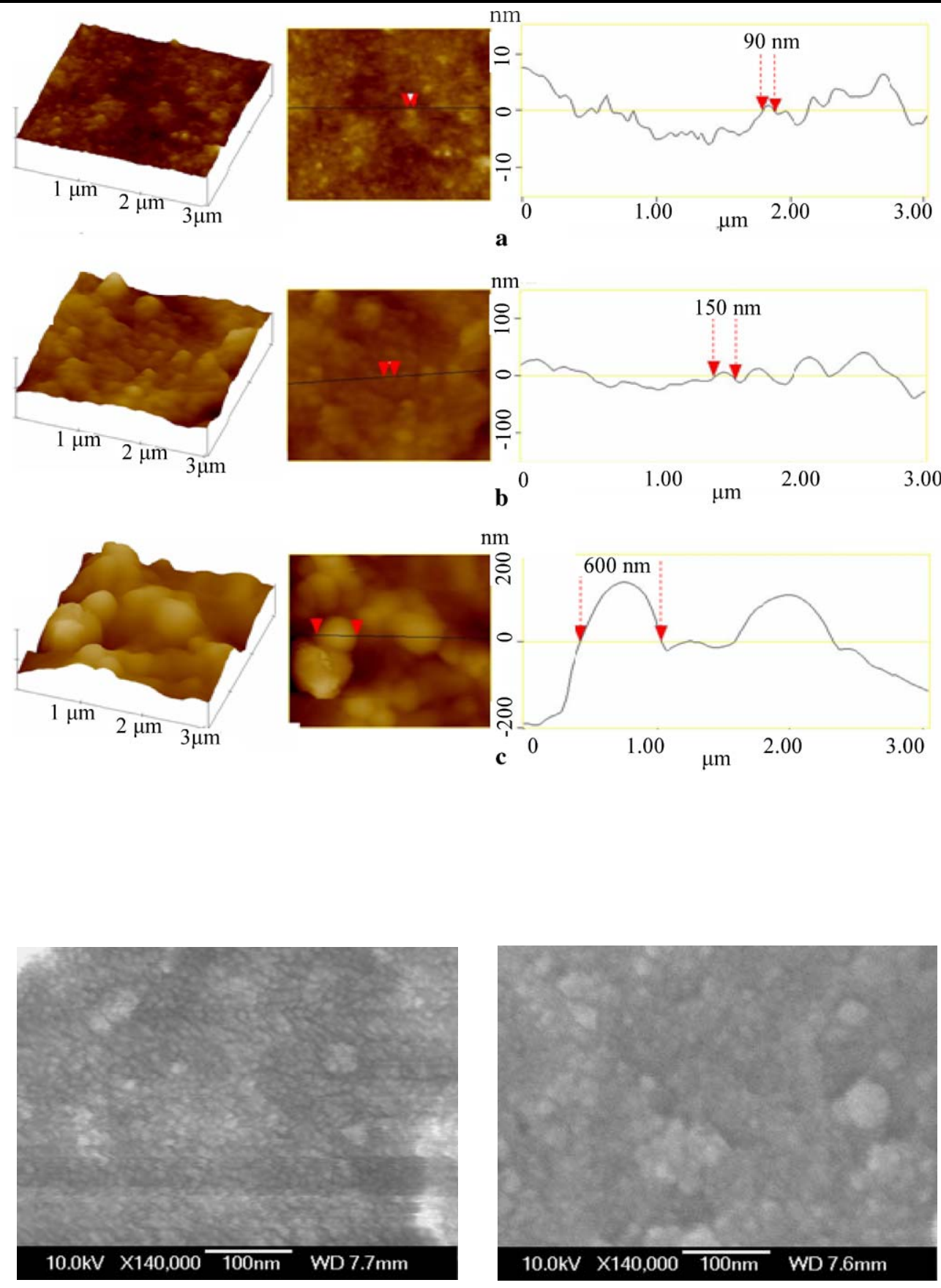

a

b

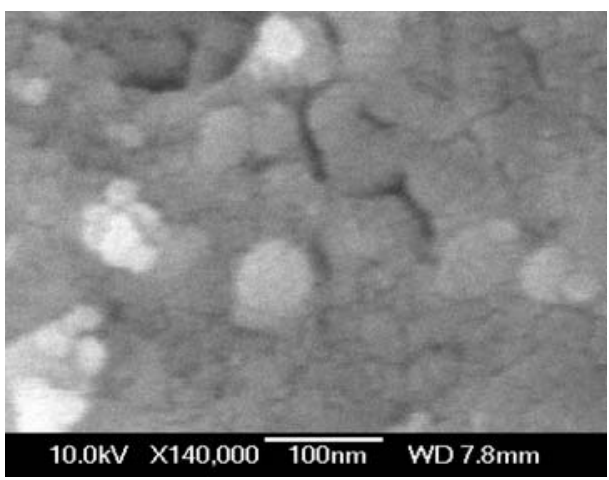

c 
Fig. 7 EDX spectra of copper nanoink sintered at different light intensities

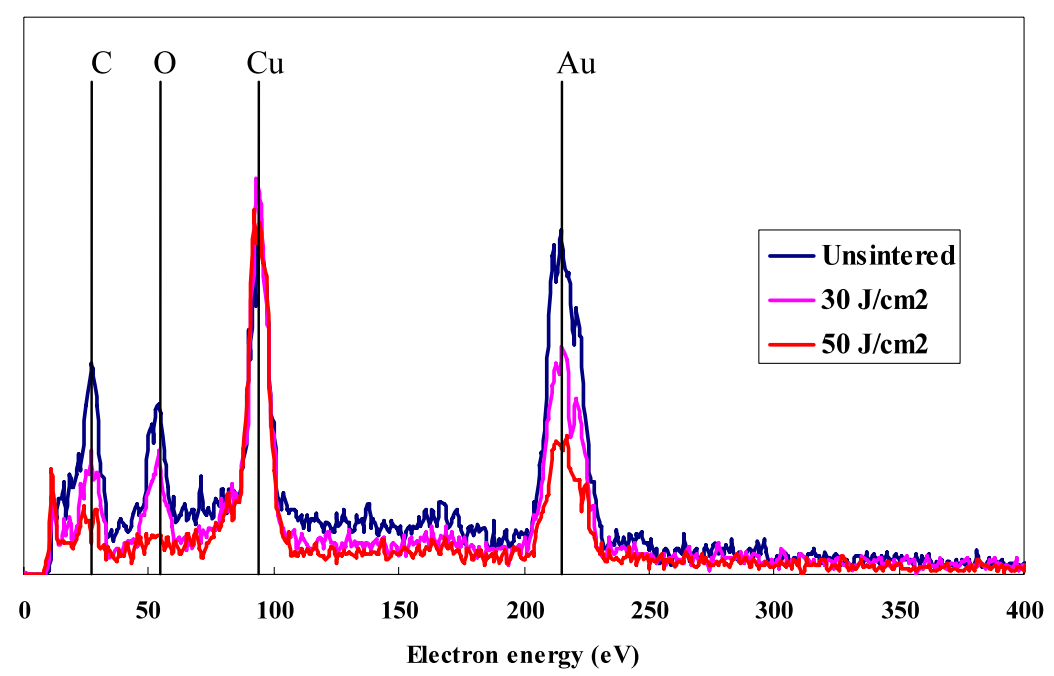

A 2D X-ray image showing the interface of the sintered copper layer and the substrate is presented in Fig. 10. No delaminations and pores between the sintered copper film and the polymer substrate were found through all cross-sections of the specimen, which reveals that the adhesion quality of the interface is good, Fig. 11(a). Also, the adhesion strength between the printed electrode and all of the polymer substrates was found to be reliable from a simple scratch test using a diamond-tip pen, Fig. 11(b).

In order to investigate the sintering mechanism of the copper nanoink by the intense pulsed light, the melting temperature of metallic nanoparticles was calculated by the following equation [9]:

$T_{m}=T_{0} \times\left(1-\frac{2}{\rho_{s} L r}\left[\gamma_{s}-\gamma_{l}\left(\frac{\rho_{s}}{\rho_{l}}\right)^{2 / 3}\right]\right)$,

where $\rho$ is the density, $\gamma$ is the surface tension, $T_{0}$ is the melting temperature of bulk metal, $L$ is the latent heat of fusion, and $r$ is the radius of the nanoparticle. The subscripts $s$ and $l$ denote solid and liquid, respectively. The material constants of copper are shown in Table 1. Equation (1) predicts that the melting temperature of copper is significantly depressed much when the particle radius is smaller than $10 \mathrm{~nm}$, Fig. 12.

The copper nanoparticles look black, not purple, because they become a very good light absorber due to their very high surface-to-volume ratio. Thus these nanoparticles can absorb the intense pulsed light very well, reaching their depressed melting temperature in a short time $(2 \mathrm{~ms})$. The short sintering time can prevent any oxidation of copper nanoparticles even in an ambient condition.

Figure 13 shows images of the stamped and sintered nanoink on various polymer substrates. There is no damage in any of the polymer substrate films, including the polyethylene film whose melting temperature is quite low, only copper nanoink $(17.2 \mu \Omega \mathrm{cm})$ reported by Park et al. [3]. 
Fig. 8 XRD patterns of copper nanoink sintered at different light intensities

Fig. 9 3D X-ray tomographs of copper nanoink fully sintered at $50 \mathrm{~J} / \mathrm{cm}^{2}$ : (a) cross-sectional view; (b) 3D view
Fig. 10 Electrical resistivity of copper nanoink changing with light intensity
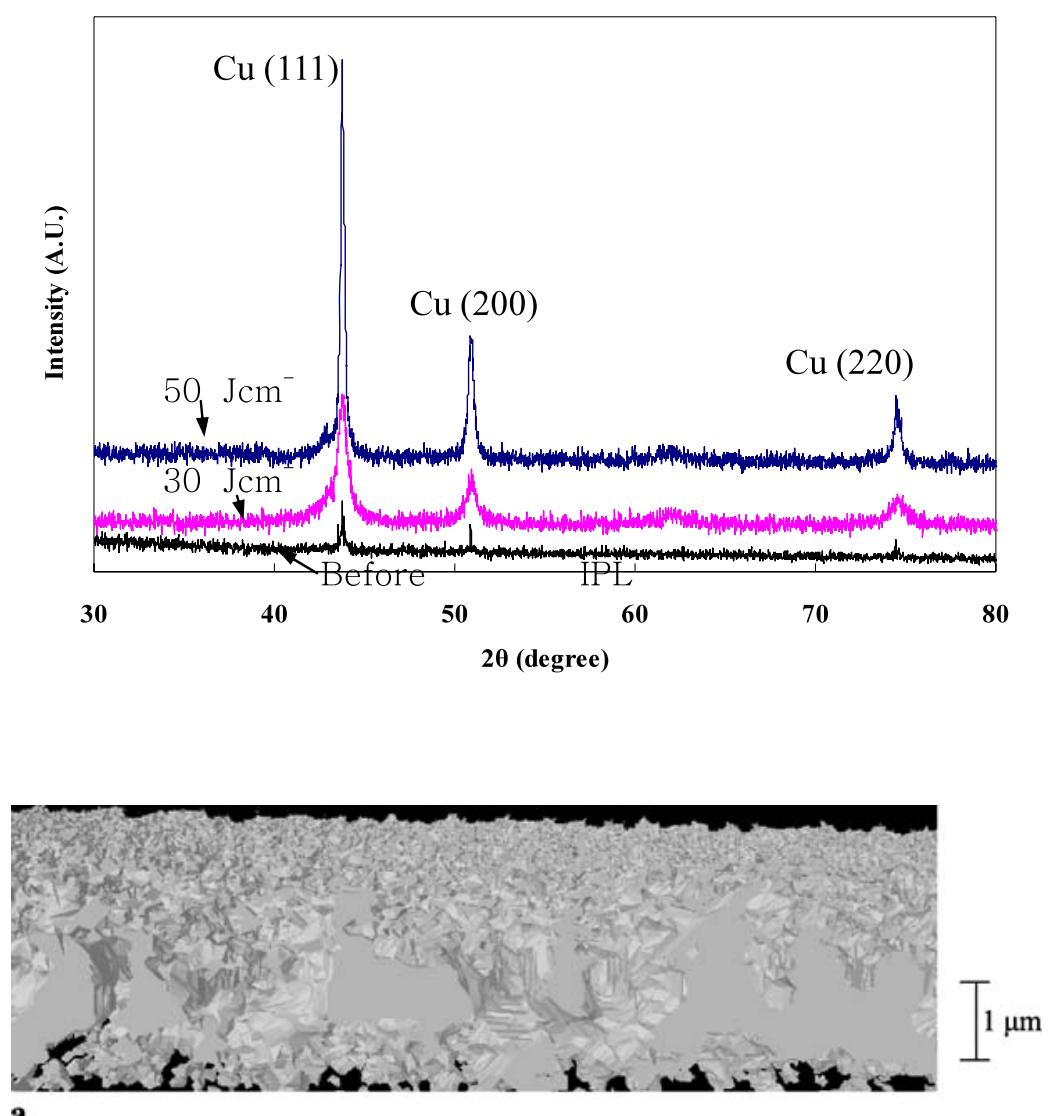

a
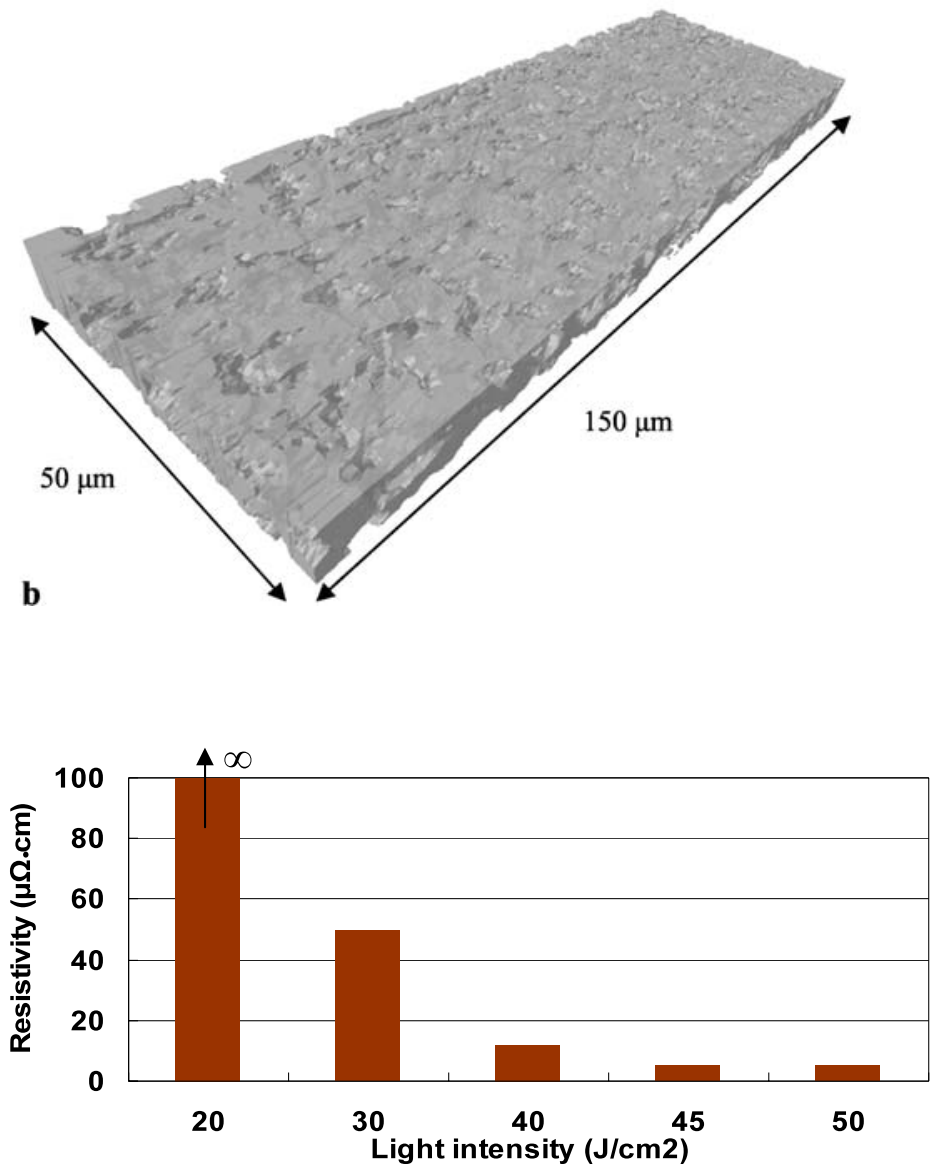


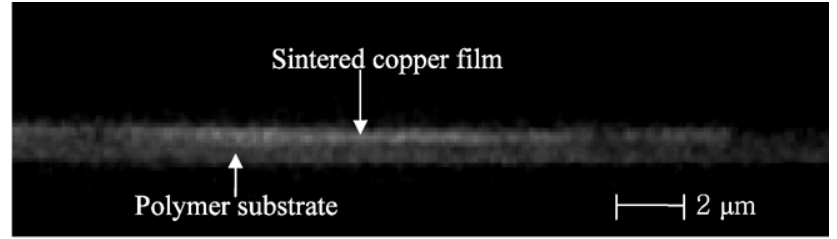

$\mathbf{a}$

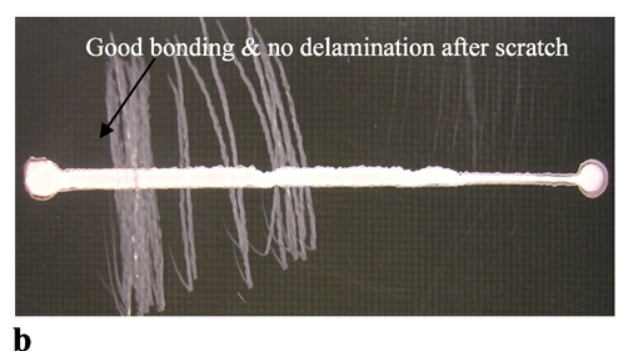

Fig. 11 Adhesion property of the interface between the sintered copper film and polymer substrate: (a) 2D X-ray tomograph of the interface; (b) scratch test result

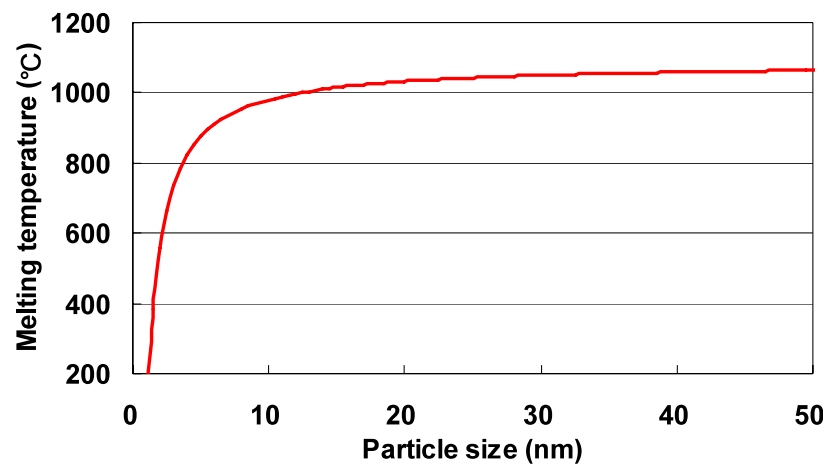

Fig. 12 Predicted melting temperature of copper nanoparticles changing with particle size about $100^{\circ} \mathrm{C}$. The reason for the success of such selective sintering can be explained as follows.

Suppose an IPL with $1 \mathrm{~J} / \mathrm{cm}^{2}$ is irradiated onto a $10-\mu \mathrm{m}$ thick copper nanoink film painted over a polyethylene film $100 \mu \mathrm{m}$ thick. Assume further that all of the light energy is absorbed into both layers without scattering and reflection. The resulting temperature increase of each material can be estimated by a lumped mass method as follows, Fig. 14:

$\Delta T=\frac{E}{\rho C_{p} V}=\frac{E}{\rho C_{p} A t}=\frac{\text { Energy density }}{\rho C_{p} t}=\frac{1 \mathrm{~J} / \mathrm{cm}^{2}}{\rho C_{p} t}$,

where $C_{p}$ and $t$ are the heat capacity and the film thickness, respectively.

Using the material properties in Table 2 yields the temperature rises of the copper and polyethylene films to be 297 and $57^{\circ} \mathrm{C}$, respectively. Furthermore, since the polymer is a very poor conductor, as shown in Table 2 , the hot copper film will heat the cool polymer only at the interface region. The resulting local melting may help the adhesion between the polymer and nanoparticle films. Therefore, the IPL sintering is an excellent fabrication process for printed electronics using low-temperature polymer substrates.

Table 1 Physical constants of copper [10]

\begin{tabular}{lll}
\hline & Solid & Liquid \\
\hline Specific gravity, $\rho\left(\mathrm{kg} \mathrm{m}^{-3}\right)$ & 8960 & 7998 \\
Surface tension, $\gamma\left(\mathrm{J} \mathrm{m}^{-2}\right)$ & 1.8 & 1.1 \\
Latent heat of fusion, $L\left(\mathrm{~J} \mathrm{~kg}^{-1}\right)$ & $2.05 \times 10^{5}$ & - \\
\hline
\end{tabular}

Fig. 13 Photographs of sintered copper nanoink on:

(a) polyimide film; (b) glass fiber BT (bismaleimide triazine) composite; and (c) polyethylene film

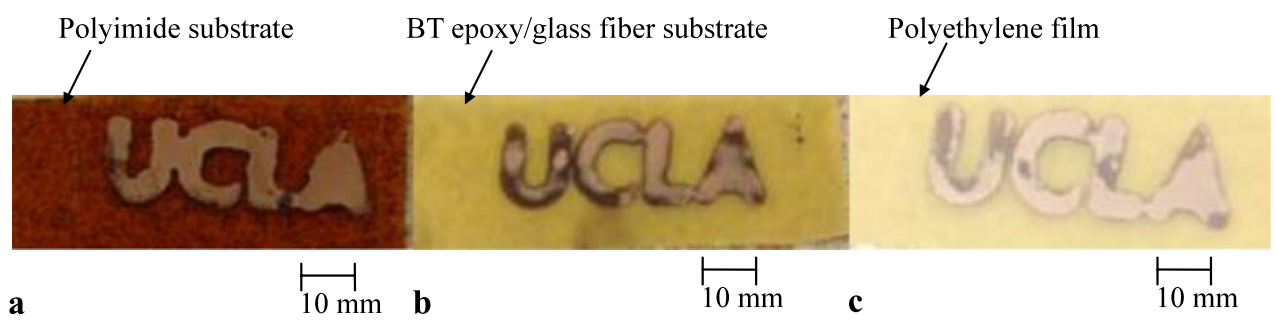

Fig. 14 Schematic of selective flash lamp sintering

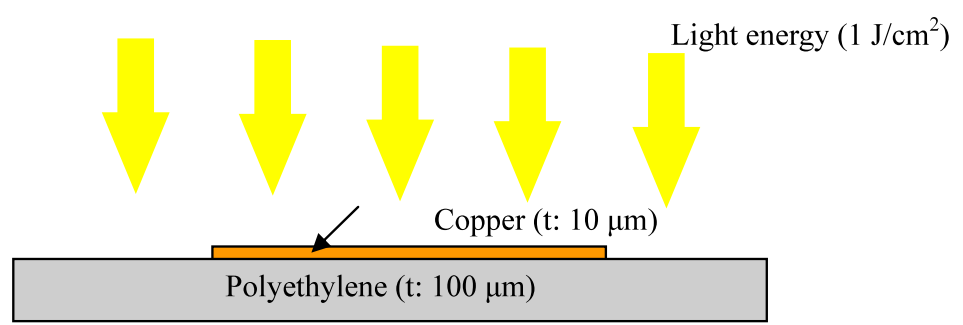


Table 2 Thermal properties of substrate materials

\begin{tabular}{lcllc}
\hline Material & $\begin{array}{l}\text { Thermal } \\
\text { conductivity } \\
(\mathrm{W} / \mathrm{mK})\end{array}$ & $\begin{array}{l}\text { Heat } \\
\text { capacity } \\
(\mathrm{J} / \mathrm{g} / \mathrm{K})\end{array}$ & $\begin{array}{l}\text { Density } \\
\left(\mathrm{g} / \mathrm{cm}^{3}\right)\end{array}$ & $\begin{array}{l}\text { Melting } \\
\text { temperature } \\
\left({ }^{\circ} \mathrm{C}\right)\end{array}$ \\
\hline Copper & 170 & 0.386 & 8.71 & 1084 \\
Polypropylene (PP) & 0.12 & 1.925 & 0.95 & 160 \\
Polyehylene terephthalate (PET) & 0.24 & 1.0 & 1.37 & 260 \\
High density polyethylene (HDPE) & 0.42 & 1.85 & 0.941 & 100 \\
BT core & 0.35 & 1.2 & 1.91 & $300(\mathrm{Tg})$ \\
\hline
\end{tabular}

\section{Conclusions}

An intense pulsed light (IPL) sintering system has been developed to sinter copper nanoink on low-temperature polymer substrates. The IPL can sinter the copper nanoink without damaging the polymer substrates when a light intensity of $50 \mathrm{~J} / \mathrm{cm}^{2}$ is used at a distance of $14 \mathrm{~mm}$ away. The sintered copper film has a grainy structure with neck-like junctions. The film has $5 \mu \Omega \mathrm{cm}$ of electrical resistivity which is one third that of previously reported thermally sintered copper nanoink. The developed IPL sintering technique can be used for large area printed electronics on low-temperature polymer substrates with almost instant cycle time.

Acknowledgements The present paper is based on work supported by the Air Force Office of Scientific Research through a MURI grant FA9550-06-1-0326 to the University of Washington. Appreciation is extended to Dr. B. Les Lee for his encouragement and support. The authors are grateful to Dr. Jae-Woo Joung and Dr. Seon-Hui Jang, Samsung Electro-Mechanics, for providing the $\mathrm{Cu}$ nanoink and BT cores.

Open Access This article is distributed under the terms of the Creative Commons Attribution Noncommercial License which permits any noncommercial use, distribution, and reproduction in any medium, provided the original author(s) and source are credited.

\section{References}

1. M. Berggern, D. Nilsson, N.D. Robinson, Nat. Mater. 6, 3-5 (2007)

2. D.J. Kim, J.H. Moon, Electrochem. Solid-State Lett. 8(11), J30J33 (2005)

3. B.K. Park, D.J. Kim, S.H. Jeong, J.H. Moon, J.S. Kim, Thin Solid Films 515, 7706-7711 (2007)

4. S.H. Ko, H. Pan, C.P. Grigoropoulos, C.K. Luscombe, M.J. Frechet, D. Poulikakos, Appl. Phys. Lett. 90, 141103 (2007)

5. S. Kamiyama, T. Miura, Y. Nara, Electrochem. Solid-State Lett. 8(12), G367-G370 (2005)

6. W. Skorupa, D. Panknin, M. Voelskow, W. Anwand, T. Gebel, R.A. Yankov, S. Paul, W. Lerch, Mater. Res. Soc. Proc. 810, C4.16 (2004)

7. http://optoelectronics.perkinelmer.com/content/RelatedLinks/ CAT_flash.pdf

8. A.V. Shyichuk, J.R. White, I.H. Craig, I.H. Syrotynska, Polym. Degrad. Stab. 80, 415-419 (2005)

9. P.A. Buffat, J.P. Borel, Phys. Rev. A 13, 2287-2298 (1976)

10. T. Mastumoto, H. Fujii, T. Ueda, M. Kamai, K. Nogi, Meas. Sci. Technol. 16, 432-437 (2005) 